\title{
ANÁLISE DA RELAÇÃO ENTRE FORÇA E MOVIMENTO EM UMA REVISTA DE DIVULGAÇÃO CIENTÍFICA
}

\section{Analysis of the relation between force and motion in a scientific divulgation magazine}

\author{
Luciano Carvalhais Gomes ${ }^{1}$ \\ Polônia Altoé Fusinato ${ }^{2}$ \\ Marcos César Danhoni Neves ${ }^{3}$
}

\begin{abstract}
Resumo: O objetivo desta pesquisa foi fazer uma análise crítica das concepções alternativas sobre força e movimento na revista Superinteressante. Para embasar essa análise, fizemos uma revisão bibliográfica sobre o tema, abrangendo desde a teoria dos movimentos naturais de Aristóteles até as três leis de Newton. Em seguida, fizemos uma comparação das concepções encontradas em várias pesquisas sobre esse assunto com as desses pensadores. Guiados por essa revisão bibliográfica, concluímos que muitas das concepções dos estudantes sobre força e movimento estão presentes na revista, mas em percentagem menor, comparadas com as encontradas nessas pesquisas. O que exige, dos educadores interessados na aprendizagem significativa dos seus alunos, cuidados especiais em sua utilização como um recurso didático.
\end{abstract}

Palavras-chave: Ensino de Física. Concepções alternativas. Força e movimento. Análise de conteúdo. Divulgação científica.

\begin{abstract}
This paper deals with a critical analysis about alternative conceptions on force and motion in the Superinteressante Magazine. This analysis was based on a bibliography review about this subject, from Aristotle's natural motion theory to the three Newton's laws of motion. Afterwards, we made a comparison between the conceptions found in various researches about this matter and that of those thinkers. Guided by this review, we conclude that many of students' conceptions about force and motion are present in the magazine, but in a lower percentage, compared to those found in the review. The research outcomes show to the educators interested in their students' meaningful learning, special care when using this magazine as didactical resource.
\end{abstract}

Keywords: Physics teaching. Alternative conceptions. Force and motion. Content analysis. Scientific divulgation.

${ }^{1}$ Licenciatura plena em Física, doutorando em Educação para a Ciência e o Ensino de Matemática. Docente, Departamento de Física, Universidade Estadual de Maringá (UEM). Maringá, PR, Brasil.

<carvalhaisgomes@uol.com.br>

${ }^{2}$ Bacharelado em Matemática, doutora em Educação. Docente aposentada, Departamento de Física, UEM. Maringá, PR, Brasil. <poly@dfi.uem.br>

3 Licenciado em Física, pós-doutor em Educação para a Ciência. Docente, Departamento de Física, UEM.

Maringá, PR, Brasil.<macedane@yahoo.com>

${ }^{1}$ Rua Campos Sales, 954

Zona 07

Maringá, PR

$87.020-080$

341

Ciência : Ẽ Educação, v. 16, n. 2, p. 341-353, 2010 
Gomes, L. C.; Fusinato, P. A.; Neves, M. C. D.

\section{Introdução}

Podemos considerar que o interesse pelos conhecimentos prévios dos estudantes começou junto com o construtivismo, em 1919, quando Piaget aceita o convite para trabalhar no laboratório de Alfred Binet, auxiliando na investigação do desenvolvimento intelectual da criança a partir de testes de inteligência padronizados elaborados pelo investigador francês. A tarefa do pesquisador suíço consistia em classificar, simplesmente, as respostas em certas ou erradas; mas ele descobre, de imediato, que era muito mais interessante tentar descobrir as razões dos fracassos (FERREIRO, 2001). Disposto a confirmar a sua hipótese, inicia um diálogo clínico com as crianças, afastando-se radicalmente das normas do teste, com a intenção de "[...] descobrir quais eram os processos de raciocínio que conduziam às respostas erradas e os que conduziam às respostas corretas" (FERREIRO, 2001, p. 108). Deste modo, descobre que raciocínios aparentemente simples apresentavam dificuldades, ainda desconhecidas, até a faixa etária de 10-11 anos.

Dessas primeiras experiências, surge uma metodologia e uma problemática nova: deixar de considerar as respostas erradas como um déficit, uma carência, e considerá-las em sua própria originalidade; tentar descobrir uma lógica dos erros; questionar os processos subjacentes às respostas, em vez de se contentar em catalogá-las. E, para consegui-lo, inventar uma metodologia adequada, que reúna as vantagens do controle experimental rigoroso com a flexibilidade dos interrogatórios utilizados na clínica psiquiátrica. (FERREIRO, 2001, p. 108, grifo nosso)

Aproveitando-se dos estudos iniciados pelo psicólogo suíço e de suas conclusões, a partir da década de 1970, observa-se "[...] entre os investigadores em ensino de ciências um grande empenho em estudar mais profundamente as noções que os estudantes trazem para a sala de aula, previamente ao ensino formal" (NARDI e GATTI, 2005, p. 145). Apesar de a teoria piagetiana do conhecimento não ter cunho pedagógico, ele não descartou a possibilidade de ela ser utilizada para esse fim:

O problema da educação interessa-me extremamente, porque tenho a impressão de que há muitíssimo que reformar e que transformar, mas penso que o papel do psicólogo é, antes de mais nada, mostrar os fatos que o pedagogo pode utilizar, e não se pôr em seu lugar para lhe dar conselhos. Corresponde ao pedagogo ver como pode utilizar o que o psicólogo the oferece. (PIAGET apud FERREIRO, 2001, p. 98 , grifo nosso)

De acordo com Nardi e Gatti (2005), algumas das primeiras pesquisas em educação sobre as ideias prévias dos estudantes em relação aos fenômenos da natureza são creditadas a Doran (1972), Viennot (1979), Watts e Zylbertajn (1981) e Driver (1985). Esses estudos foram realizados na área de mecânica e mostraram que existem padrões de respostas a várias situa- 
ções físicas em contradição com o conhecimento científico, tornando-se um obstáculo à sua assimilação. O que não causaria tanto espanto se não fosse o fato de essas concepções persistirem após anos de instrução, sendo encontradas, inclusive, entre professores em situação de ensino. No início, essas concepções receberam nomes variados, por exemplo: "pré-concepções" e "misconception". Após as críticas de Driver e Easley (1978) a estas denominações, o termo concepções alternativas ficou como o preferido pelos pesquisadores. Pois, "pré-concepções" e "misconception" remetem à ideia de um conhecimento incompleto e errôneo que precisa a todo custo ser modificado, enquanto concepções alternativas sugerem que estas têm toda uma estrutura lógica e são úteis para interpretar os fenômenos tanto quanto as concepções científicas. Depois de inúmeras pesquisas, conhecemos uma gama enorme de concepções alternativas. Por exemplo, para ficarmos somente na Física, sabe-se que muitos estudantes acreditam que o conceito de movimento está associado à aplicação de uma força (POZO, 1987; DI SESSA, 1982); que a corrente elétrica é consumida em uma bateria (SAXENA, 1992); que o calor está contido nos corpos (ROGAN, 1988), entre outros exemplos. A origem destas concepções é atribuída à interação do sujeito com os fenômenos a sua volta, desde tenra idade, e ao convívio social.

No discurso diário e através dos meios de comunicação de massa, nossas crianças são confrontadas com suposições implícitas sobre como os objetos se movem, sua energia e suas propriedades, que podem estar em conflito direto com a explicação científica que aprendem na escola. Fora do laboratório escolar, esses adolescentes estão sendo continuamente socializados em um repertório completo de explicações não científicas. Um exame de reportagens de jornal e da linguagem cotidiana torna clara a disseminação deste processo subversivo. Segundo a autora, não haveria meios para extinguir as noções cotidianas, assinalando que os estudantes deveriam ser capazes de pensar e operar em dois diferentes domínios de conhecimento e distinguir entre eles. (SOLOMON, 1983 apud NARDI e GATTI, 2005 , p. 157 , grifo nosso)

Nesse contexto, surgiu a ideia de nossa pesquisa. Ao observarmos uma tendência crescente de utilização de textos de divulgação científica de jornais e de revistas nas aulas de Física, indagamo-nos: A revista "Superinteressante" reforça ou induz as concepções alternativas sobre a relação entre força e movimento? Caso afirmativo, isso acontece de modo explícito ou implícito? Escolhemos a "Superinteressante" por ser a revista de divulgação científica de maior tiragem no país, sendo a mais conhecida e utilizada pelos professores do Ensino Médio. Desse modo, a nossa proposta foi fazer um levantamento bibliográfico sobre os principais trabalhos relacionados com as concepções alternativas sobre a relação entre força e movimento; e, em seguida, com o auxílio dos procedimentos metodológicos da análise de conteúdo propostos por Bardin (1977), identificar, nos artigos dessa revista, as formas de apresentação de situações envolvendo esses conceitos científicos que possam vir a reforçar ou induzir essas concepções alternativas em seus leitores. 
Gomes, L. C.; Fusinato, P. A.; Neves, M. C. D.

\section{Procedimentos metodológicos}

\section{Pré-análise}

Em um primeiro momento, fizemos uma revisão bibliográfica sobre o tema, que nos ajudou a escolher quatro palavras-chave: "força", "velocidade", "aceleração" e "movimento". O nosso interesse era compreender "De que modo?" os artigos relacionavam força com os outros três conceitos. Então, pesquisamos essas palavras no corpo textual da revista, utilizando o sistema de busca presente na coleção em CDs com 18 anos de publicação. Nessa, constavam 296 exemplares - 81 edições especiais e 215 edições comuns - abrangendo desde setembro de 1987 até junho de 2005.

Encontramos 1.658 artigos com a palavra-chave "força", 858 com a "velocidade", 83 com a "aceleração" e 1.238 com a "movimento". A unidade de registro ${ }^{4}$ central de nossa pesquisa era a palavra-polo "força", então, escolhemos apenas os artigos em que ela estava presente junto com alguma das outras três - velocidade, aceleração ou movimento -, perfazendo um total de 759 artigos, essa foi a nossa primeira amostra. Após uma "leitura flutuante" ${ }^{\prime \prime}$, percebemos que, em muitos desses artigos, ou as palavras-chave estavam em um contexto fora do interesse da pesquisa, ou não existia uma relação entre as mesmas, sendo, portanto, desconsiderados. Isso aconteceu, sobretudo, pelo fato de o sistema de busca da revista não encontrar apenas a palavra "força" isolada, incluindo todas palavras onde a grafia "força" estivesse presente. Destacamos, abaixo, alguns trechos dos artigos que não foram considerados para a amostra final por esses dois motivos:

\section{1) Palavras-chave em um contexto fora do interesse da pesquisa:}

1.a) SINTO MUITO (CD 10, jun. 2005, ed. 214, p. 76-81)

"Casos como o dele reforçam a teoria de que a percepşão das coisas não depende $[\ldots] ”$.

"Oliver Sacks cita o caso de um professor de música com um processo degenerativo nas partes visuais do seu cérebro que foi aos poucos perdendo a capacidade de enxergar o todo de uma imagem. Identificava apenas os detalhes ou os movimentos".

\footnotetext{
4 "É a unidade de significação a codificar e corresponde ao segmento de conteúdo a considerar como unidade de base, visando a categorização e a contagem frequencial. A unidade de registro pode ser de natureza e de dimensões muito variáveis" (BARDIN, 1977, p. 104).

5 "A primeira actividade consiste em estabelecer contacto com os documentos a analisar e em conhecer o texto deixando-se invadir por impressões e orientações. Esta fase é chamada de leitura $<<$ flutuante $>>$, por analogia com a atitude do psicanalista. Pouco a pouco, a leitura vai-se tornando mais precisa, em função de hipóteses emergentes, da projeção de teorias adaptadas sobre o material e da possível aplicação de técnicas utilizadas sobre materiais análogos”. (BARDIN, 1977, p. 96)
} 
Análise da relação entre força e movimento ...

1.b) O QUE É QUE A CABALA TEM? (CD 10, jun. 2005, ed. 214, p. 64-69)

"Hoje já não é mais assim. Alguns cabalistas têm se esforcado em tradužir [...]".

“[...] diversos movimentos misticos emergiram nos últimos anos [...]”.

1.c) DEUS EXISTE? (CD 6, jan. 2001, ed. 160, p. 60-65)

"Alguma transformação radical deve ter ocorrido para que a crença em Deus, assunto que havia se tornado tabu em laboratórios e universidades, renascesse com tanta forca".

"Ele mostrou que mesmo a mecânica de Newton não era deterministica no sentido que se pensava. Ai, veio a mecânica quântica e introduriu o conceito de que é impossivel se conbecer simultaneamente a posição e o movimento de uma partícula".

\section{2) Palavras-chave sem relação entre si:}

2.a) EXPULSOS DO BERÇO (CD 5, fev. 2000, ed. 149, p. 80-83)

"A força gravitacional dos asteróides também pode ter ajudado a tirar Netuno da órbita. Bilhões de rochas, dando pequenos puxões durante um tempo imenso, poderiam afastá-lo do Sol. Mas os cálculos indicam que a gravidade jupiteriana foi a forsa dominante do processo".

"As simulações eletrônicas alteraram as concep̣ções sobre a origem dos mundos. Antes se achava que eles tinham sido criados nas órbitas que ocupam atualmente. Mas, desde o início dos anos 70, o computador passou a contar uma outra história. Ele sugeriu que os planetas surgem em grupos. Com bumor, os astrônomos dão a esse movimento de astros enormes, que aparecem coletivamente e dominam a formação de planetas menores, o nome de crescimento oligárquico".

2.b) TÁ COM PRESSA? PASSA POR CIMA! (CD 5, jul. 1999, ed. 142, p. 26-33)

"A 200 quilometros por hora, as pequenas asas traseiras respondem por 28\% da sustentação no ar. O restante é gerado pela força dos motores (10\%), pelo fluxo de vento que passa sobre as turbinas (46\%) e pela fuselagem do aparelho (16\%)".

"A tecnologia para isso já existe. Falta aperfeiçoá-la. A idéia é colocar em órbita um conjunto de satélites que cubra toda a superficie do planeta. Cada Skycar enviará um sinal constante para o espaço. O satélite recebe a informação e a devolve à aeronave, indicando posição, altitude, velocidade e rota adequadas. O computador de bordo apenas obedece. O dono só precisará ligá-lo e dizer para onde quer ir". 
Gomes, L. C.; Fusinato, P. A.; Neves, M. C. D.

2.c) DELÍRIO DE VOAR (CD 5, jun. 1999, ed. 141, p. 36-43)

'Em 1908, o marquês d'Ecquevilley-Montjustin construiu este estranbo multiplano constituído de telas fixadas por uma armação de tubos de aço. Uma bélice de 2,5 metros de comprimento, movida por um motor de 7 cavalos, deveria produzir uma força ascendente e levantá-lo. Segundo o inventor, o aparelho era sólido, leve, barato e maleável. Mas falhou no primeiro teste. Nunca voou”.

"Trajan Vuia (1872-1951) é o pioneiro aviador da Romênia. Engenheiro e aeronauta, começou a construir aviöes em Paris em 1900. Em 1902, montou um veículo com rodas, movido por um motor de automóvel de 25 cavalos, que deveria decolar após forte aceleracão. A máquina, entretanto, era muito pesada e não saiu do chão".

Depois dessa longa e árdua pré-análise, sobraram 55 artigos para a amostra final. Comparados com a quantidade de artigos presentes nos 18 anos da revista, podemos dizer que se trata de uma amostra pequena. Mas, ao falar sobre a escolha da amostra em pesquisas que envolvem a análise de conteúdo, Bauer (2002, p. 197) faz o seguinte comentário: "Uma amostra pequena, sistematicamente selecionada, é muito melhor do que uma grande amostra de materiais escolhidos ao acaso". Foi o que fizemos. A Tabela 1 apresenta os artigos selecionados.

\section{Exploração do material}

Escolhidos os artigos, lemos cada um novamente de uma maneira mais minuciosa definindo as unidades de contexto ${ }^{6}$. Essas variaram muito de um texto para outro, indo desde o próprio parágrafo no qual estava a unidade de registro em alguns artigos, até o texto todo em outras situações. A análise destinava-se a categorizar a concepção entre força e movimento, presente no texto, em aristotélica, newtoniana ou indefinida. Entendemos por categorizar como:

[...] uma operação de classificação de elementos constitutivos de um conjunto, por diferenciação e, seguidamente, por reagrupamento segundo o género (analogia), com os critérios previamente definidos. As categorias são rubricas ou classes, as quais reunem um grupo de elementos (unidades de registo, no caso da análise de conteúdo) sob um título genérico, agrupamento esse efectuado em razão dos caracteres comuns desses elementos. (BARDIN, 1977, p. 117)

6 "A unidade de contexto serve de unidade de compreensão para codificar a unidade de registo e corresponde ao segmento da mensagem, cujas dimensões (superiores às da unidade de registo) são óptimas para que se possa compreender a significação exacta da unidade de registo" (BARDIN, 1977, p. 107). 
Análise da relação entre força e movimento ...

Tabela 1. Artigos selecionados para a análise final.

\begin{tabular}{|c|c|c|c|c|c|c|}
\hline \multicolumn{7}{|c|}{ Amostra final } \\
\hline Ordem & CD & Mês & Ano & Edição & Páginas & Título \\
\hline 1 & 10 & Maio & 2005 & 213 & $78-83$ & Big Bang \\
\hline 2 & 10 & Novembro & 2004 & 206 & $72-76$ & Corra para não cair \\
\hline 3 & 10 & Setembro & 2004 & 204a (esp.) & $70-73$ & Em ritmo acelerado \\
\hline 4 & 9 & Abril & 2004 & 65 (esp.) & 38 & Parto a jato \\
\hline 5 & 9 & Abril & 2004 & 65 (esp.) & 39 & Para o infinito... e além \\
\hline 6 & 9 & Janeiro & 2004 & 196 & $68-72$ & O nada é quase tudo \\
\hline 7 & 9 & Novembro & 2003 & 62 (esp.) & 12 & Por que os ciclistas usam roupas de lycra? \\
\hline 8 & 9 & Agosto & 2003 & 191 & $76-80$ & Nem tudo é relativo \\
\hline 9 & 9 & Julho & 2003 & 190 & $30-31$ & Como ficaria a F-1 sem as restrições no regulamento \\
\hline 10 & 6 & Outubro & 2001 & 169 & 92 & Acelera, mané! \\
\hline 11 & 6 & Julho & 2001 & 166 & $55-61$ & Muito além do Big Bang \\
\hline 12 & 6 & Junho & 2001 & 165 & $40-41$ & Como funciona o fliperama? \\
\hline 13 & 6 & Junho & 2001 & 165 & $64-67$ & A arte de voar sem sair do chão \\
\hline 14 & 6 & Novembro & 2000 & 158 & 46 & E se... A Terra tivesse a gravidade de Marte \\
\hline 15 & 5 & Março & 2000 & 150 & $62-67$ & Caçadores de explosão \\
\hline 16 & 5 & Fevereiro & 2000 & 149 & 26 & Os rapidinhos do sistema solar \\
\hline 17 & 5 & Fevereiro & 2000 & 149 & $80-83$ & Expulsos do berço \\
\hline 18 & 5 & Outubro & 1999 & 145 & 12 & Um átomo ajuda a bater recordes \\
\hline 19 & 5 & Outubro & 1999 & 145 & 20 & É proibido virar cambalhotas no ar \\
\hline 20 & 8 & Agosto & 1999 & $27 a$ (esp.) & $12-13$ & O caçador de galáxias \\
\hline 21 & 5 & Agosto & 1999 & 143 & 11 & A ventania que breca o planeta \\
\hline 22 & 5 & Maio & 1999 & 140 & $46-51$ & Universo? Qual deles? \\
\hline 23 & 5 & Março & 1999 & 138 & 73 & A crise do Big Bang \\
\hline 24 & 5 & Janeiro & 1999 & 136 & 21 & Tem uma mosca no meu elevador \\
\hline 25 & 5 & Dezembro & 1998 & 135 & $90-93$ & Olha lá a europa \\
\hline 26 & 5 & Novembro & 1998 & 134 & 124 & Sombra e água fresca para o coração no espaço \\
\hline 27 & 5 & Junho & 1998 & 129 & $38-43$ & Velocidade máxima \\
\hline 28 & 5 & Junho & 1998 & 129 & 91 & Einstein acerta até quando erra \\
\hline 29 & 5 & Março & 1998 & 126 & $68-73$ & A dama dos anéis \\
\hline 30 & 5 & Janeiro & 1998 & 124 & 24 & Pra baixo o santo ajuda, pra cima a coisa muda \\
\hline 31 & 4 & Setembro & 1997 & 120 & $75-79$ & Pinças de luz \\
\hline 32 & 4 & Junho & 1997 & 117 & 12 & Einstein na corda bamba \\
\hline 33 & 4 & Junho & 1997 & 117 & $64-69$ & Você só enxerga 1\% do universo \\
\hline 34 & 4 & Setembro & 1996 & 108 & 70 & O irmão de Júpiter e seu Sol viajante \\
\hline 35 & 4 & Abril & 1996 & 103 & $26-29$ & Atletas de aço \\
\hline 36 & 4 & Abril & 1996 & 103 & $64-69$ & Supernovas, relógios cósmicos \\
\hline 37 & 4 & Janeiro & 1996 & 100 & 12 & Não levita mas também "voa" sobre os trilhos \\
\hline 38 & 4 & Dezembro & 1995 & 99 & $46-55$ & A última cartada de Einstein \\
\hline 39 & 3 & Dezembro & 1994 & 87 & $25-29$ & Big Bang: Fechado para balanço \\
\hline 40 & 3 & Julho & 1994 & 82 & $18-23$ & Atenção, tripulação! \\
\hline 41 & 3 & Julho & 1994 & 82 & $78-81$ & Supermotores para superaviões \\
\hline 42 & 3 & Junho & 1994 & 81 & $34-38$ & Delta clipper: este foguete vai e volta \\
\hline 43 & 3 & Abril & 1994 & 79 & $16-23$ & Acima do céu \\
\hline 44 & 3 & Março & 1994 & 78 & $52-57$ & Tudo o que você queria saber sobre o Big Bang \\
\hline 45 & 3 & Janeiro & 1994 & 76 & $36-41$ & Ciência fora da sala de aula \\
\hline 46 & 3 & Dezembro & 1993 & 75 & $60-65$ & Inteligência em movimento \\
\hline 47 & 3 & Outubro & 1992 & 61 & $21-26$ & A implacável dinâmica dos carros \\
\hline 48 & 2 & Agosto & 1991 & 47 & $56-60$ & Supercargueiros no ar \\
\hline 49 & 2 & Abril & 1991 & 43 & $22-28$ & Das pistas para as estradas \\
\hline 50 & 2 & Março & 1991 & 42 & $54-58$ & O vaivém do bumerangue pelo tempo \\
\hline 51 & 2 & Agosto & 1990 & 35 & $50-55$ & Eletricidade sob suspeita \\
\hline 52 & 1 & Janeiro & 1989 & 16 & $18-23$ & A ciência vai ao parque \\
\hline 53 & 1 & Setembro & 1988 & 12 & $68-74$ & O mistério do grande atrator \\
\hline 54 & 1 & Julho & 1988 & 10 & $60-65$ & As imagens da relatividade \\
\hline 55 & 1 & Janeiro & 1988 & 4 & $84-87$ & A ciência do chute com efeito \\
\hline
\end{tabular}


A escolha dessas categorias foi consequência de um histórico que fizemos sobre a relação entre força e movimento. Partindo da teoria dos movimentos naturais de Aristóteles até as três leis de Newton, mostramos como o desenvolvimento da concepção científica sobre esse assunto esteve repleto de controvérsias, muitas ainda não resolvidas. Em seguida, fizemos um paralelo das concepções alternativas sobre a relação entre a força e movimento, encontradas em várias pesquisas, com as concepções desses pensadores. Nessa comparação, ficou evidente que a concepção newtoniana do movimento é difícil de ser assimilada por tratar de situações idealizadas que não condizem com os experimentos cotidianos.

\section{Tratamento dos resultados obtidos, inferência e interpretação}

A nossa intenção inicial era seguir o exemplo de Harres (2002) e dividir as concepções sobre a relação entre força e movimento, encontradas na revista, em cinco categorias: aristotélica, ímpetus inicial, ímpetus médio, ímpetus avançado e newtoniana. Adotando, como metodologia para a divisão das categorias do ímpetus, as mesmas três perguntas utilizadas pelo autor. Infelizmente, não foi possível pôr esta ideia em prática. A relação entre força e movimento encontrada nos artigos é pontual, ou seja, refere-se a determinados instantes da trajetória do corpo. Quando isso acontece, as únicas concepções que podem se manifestar são a aristotélica e a newtoniana.

A concepção da "física da força impressa", para ser percebida, exige uma explicação do início ao fim do movimento. Desse modo, escolhemos categorizar a concepção entre força e movimento, presente no texto, em aristotélica, newtoniana ou indefinida. Esta última categoria foi necessária, pois, em muitas reportagens analisadas, apesar de o texto mostrar uma relação entre a força e o movimento, não fica claro se o autor considera a força proporcional à velocidade ou à aceleração.

Outra dificuldade encontrada foi a de não podermos utilizar indicadores e codificadores, muito comuns em pesquisas que empregam os procedimentos metodológicos da análise de conteúdo, para auxiliar, estatisticamente, na interpretação e inferência dos dados. Por exemplo, dos 759 artigos em que apareciam a palavra-chave "força", encontramos, em 410 deles, a palavra-chave "velocidade", e, em 52, a palavra-chave "aceleração". Uma análise estatística superficial diria que cerca de $54 \%$ dos artigos da revista Superinteressante apresentam a relação $\mathrm{F}=\mathrm{kV}$, pois, força e velocidade aparecem juntas no mesmo texto. Pelo que já explicamos ao longo do trabalho, fica evidente que esta é uma conclusão completamente equivocada. Para ilustrar como categorizamos os artigos, selecionamos trechos de alguns deles. Limitaremo-nos a analisar o foco de nossa pesquisa. Imprecisão no uso de termos científicos e interpretação errônea de outras teorias físicas, por exemplo, deixaremos como sugestões para pesquisas futuras.

\section{a) Concepção aristotélica:}

a.1) COMO FICARIA A F-1 SEM AS RESTRIÇÕES NO REGULAMENTO?

(CD 9, jul. 2003, ed. 190, p. 30-31) 
Análise da relação entre força e movimento ...

"O baque de uma freada brusca numa velocidade dessas é cruel. A pressão faria o corpo do sujeito ser jogado para a frente com uma força seis vezes maior que a da gravidade (ou 'de 6 g', como dizem os técnicos). Isso pode dar num desmaio ou numa parada cardiaca".

Comentários: Ao afirmar que, em uma freada brusca, o corpo do motorista é “jogado para a frente", a reportagem passa a mensagem subliminar de que o movimento do motorista é provocado por uma força. O correto seria dizer que, por inércia, o corpo mantém a mesma velocidade que tinha no instante da freada.

a.2) OS RAPIDINHOS DO SISTEMA SOLAR (CD 5, fev. 2000, ed. 149, p. 26)

"A 58 milhões de quilômetros da sua estrela, Mercúrio equilibra a gravidade que o puxa girando à alta velocidade de 173000 quilômetros por hora. Isso gera a força oposta capaz de mantê-lo em sua órbita".

Comentários: Mercúrio não equilibra a força gravitacional do Sol, senão ele não estaria em órbita. O planeta está apenas em uma eterna queda livre em direção a essa estrela. Essa maneira de se expressar remete à ideia de que, se a força é proporcional à velocidade, então, uma "alta velocidade" é capaz de gerar uma "força".

\section{b) Concepção newtoniana:}

b.1) BIG BANG (CD 10 - MAIO 2005 - ED. 213 - PG. 78-83)

"No final dos anos 1990, por exemplo, descobriu-se que o Universo não só aumenta, como está acelerando. Alguma forç - até agora chamada de "energia escura" - está empurrando o cosmo, mas ninguém sabe muito bem o que é, nem o que ela fez desde o big-bang".

Comentários: Diferente do artigo "O caçador de galáxias", a força está corretamente associada com a expansão acelerada do Universo. É necessária uma força para acelerar a expansão do Universo, mas, para manter essa expansão, essa exigência não é obrigatória.

b.2) COMO FUNCIONA O FLIPERAMA? (CD 6, jun. 2001, ed. 165, p. 40-41)

"Esse brinquedo desafia a lei da gravidade, exigindo que se controle o movimento sempre acelerado de uma bola metálica em um plano inclinado".

Comentários: Escolhemos este trecho por acreditarmos que ele induz, implicitamente, a concepção newtoniana de movimento, por causa da afirmativa de que o movimento da bola metálica, durante o plano inclinado, é "sempre acelerado". Isso inclui o instante em que a bola para no ponto mais alto da trajetória. Pelas pesquisas que vimos, a maioria dos alunos acredita que, nesse instante, não existe aceleração, pois, velocidade nula implica força nula e, sem força, não tem como alterar a velocidade. Desse modo, o trecho analisado contraria esse esquema de raciocínio. 
Gomes, L. C.; Fusinato, P. A.; Neves, M. C. D.

c) Concepção indefinida:

c.1) POR QUE OS CICLISTAS USAM ROUPAS DE LYCRA? (CD 9, nov. 2003, ed. 62e, p. 12)

\begin{abstract}
"Uma roupa de superficie lisa é fundamental para o desempenho do ciclista, em especial nas modalidades que exigem alta velocidade. Esse tipo de tecido diminui o atrito com o ar e evita 'turbulência' no movimento. Assim, não é necessária muita força para atingir grandes velocidades', diz o professor Mauro Catani, do Instituto de Física da Universidade de São Paulo (USP). Segundo Filipe Chawvin, proprietário de uma confecção especializada em uniformes para o esporte, os fios de elastano (chamados comumente de Lycra, marca registrada da DuPont) são microfibras de borracha e representam de $7 \%$ a 20\% da composição do tecido. Há tecidos de alta performance nos quais os fios são ocos, a fim de facilitar a transpiração', di\%. Nas provas longas, que exigem resistência, os atletas costumam optar por camisetas de poliéster. 'Como não estão preocupados com a relação entre força e velocidade, eles preferem um tecido que facilite a transpiração e proporcione conforto', diz Chawin”".
\end{abstract}

Comentários: $\mathrm{O}$ texto relaciona a força com a velocidade em duas passagens, uma quando diz "[...] não é necessária muita força para atingir grandes velocidades [...]", e a outra quando explica que os ciclistas "[...] não estão preocupados com a relação entre força e velocidade, eles preferem um tecido que facilite a transpiração e proporcione conforto". Acreditamos que esses dois trechos não deixam claro se a força é proporcional à velocidade ou à variação da velocidade, por isto, definimos a concepção presente na reportagem como indefinida.

c.2) UNIVERSO? QUAL DELES? (CD 5, maio 1999, ed. 140, p. 46-51)

"Desde 1997 se desconfia que há, mesmo, uma força no espaço empurrando as galáxias para longe umas das outras (veja Velocidade máxima, na SUPER número 6, ano 12). Este ano, o efeito foi confirmado pelo astrofísico Saul Perlmutter, do Laboratório Nacional Lawrence Berkeley, nos Estados Unidos".

Comentários: Não classificamos essa reportagem dentro da categoria de concepção aristotélica por afirmar que há uma força no espaço empurrando as galáxias para longe umas das outras sem questionar a necessidade da existência dessa força para que isto aconteça. Ela também não foi categorizada como newtoniana pelo fato de não explicitar se o afastamento das galáxias ocorre de modo acelerado.

Diferente da revista Ciência Hoje, em que todos os artigos são escritos por cientistas da área, a Superinteressante utiliza jornalistas. Esses, muitas vezes, apoiam-se em opiniões de cientistas para escreverem a matéria, desse modo, a maioria das reportagens é uma mescla de conceitos. Talvez isso explique o porquê de tantas concepções de movimento indefinidas que encontramos. Por causa dessa mistura de concepções, acreditamos que o tipo de análise que fizemos não permitiria chegar a uma conclusão definitiva sobre a concepção alternativa desse ou daquele autor. Desse modo, podemos apenas estimar a probabilidade de um leitor da 
Análise da relação entre força e movimento ...

revista ser influenciado pela concepção alternativa aristotélica de movimento. Agora, podemos responder as duas perguntas que guiaram a nossa pesquisa:

- A revista Superinteressante reforça ou induz as concepções alternativas sobre a relação entre força e movimento?

- Caso afirmativo, isto acontece de modo explícito ou implícito?

A maioria das reportagens, talvez por não aprofundarem muito a questão do porquê do movimento, apresentaram uma concepção newtoniana. Nesse caso, a probabilidade de o leitor ser influenciado pelas concepções alternativas sobre a relação entre força e movimento existe, mas em proporções menores do que não ser influenciado. Além disso, em cerca de $80 \%$ das vezes, esta influência está implícita. Os trechos dos artigos que mostramos exemplificam essa nossa afirmação. O que nos auxiliou muito a perceber a relação implícita que havia foi a revisão bibliográfica que fizemos, tanto a que abordou os aspectos históricos, quanto a que mostrou as principais pesquisas sobre o tema. Entretanto, essa interpretação não deve ser generalizada, pois, na leitura dos 759 artigos selecionados na primeira amostra, notamos vários outros tipos de concepções alternativas de maior incidência e mais explícitas do que a que pesquisamos, com destaque para a origem, estrutura e evolução do Universo e o conceito de energia. Observamos, também, vários erros conceituais; imprecisão na utilização de conceitos científicos, sobretudo, os de força e energia; definições de leis físicas de forma inadequadas; entre outros equívocos.

\section{Conclusão}

A análise dos dados mostra que a probabilidade de um leitor dessa revista ter as suas concepções alternativas sobre a relação entre força e velocidade reforçadas ou induzidas é de, aproximadamente, $30 \%$ (cerca de um a cada três artigos). Essa porcentagem abaixo dos 50\% - média encontrada nas pesquisas de Viennot (1979), Watts e Zylbersztajn (1981), Peduzzi e Peduzzi (1985), Clement (1982), Sebastia (1984), McDermott (1984) e Di Sessa (1982) - pode ser explicada pelas particularidades dos instrumentos de aquisição dos dados. Ou seja, para que essa concepção seja identificada com mais intensidade, há a necessidade de se formularem situações que permitam ao investigado relacionar as grandezas força e velocidade, ou força e movimento, de uma maneira mais incisiva. Isto é fácil de ser atingido com questionários e questões abertas, mas difícil em textos com temáticas diversas. Acreditamos que essa dificuldade seja menor quando a relação entre duas ou mais grandezas físicas não está em questionamento, por exemplo, em concepções que envolvam definições do tipo "O que é energia?” e "O que é força?". Sugerimos, para uma pesquisa futura, que se verifique a validade dessa afirmação.

Outra sugestão seria comparar a análise que fizemos com as de outros professores que não têm familiaridade com as pesquisas sobre concepções alternativas desse tema. Por estarem implícitas, entendemos que muitas delas passariam despercebidas. Seria interessante, também, uma pesquisa com a mesma finalidade dessa em outras revistas de divulgação científica mais conceituadas pela comunidade acadêmico-científica, como a revista Ciência Hoje e a revista Pesquisa Fapesp. Pelo fato de os artigos dessas revistas serem escritos por autores reconhecidos por sua sólida formação científica, a tendência é que se verifique uma porcentagem menor de concepções alternativas comparadas com a da nossa pesquisa. 
Gomes, L. C.; Fusinato, P. A.; Neves, M. C. D.

\section{Referências}

BARDIN, L. Análise de conteúdo. Lisboa: Edições 70, 1977.

BAUER, M. W. Análise de conteúdo clássica: uma revisão. In: .; GASKELL, G

(Eds.). Pesquisa qualitativa com texto, imagem e som: um manual prático. 3. ed. Petrópolis: Vozes, 2002. p. 189-217.

CLEMENT, J. Student's preconceptions in introductory mechanics. American Journal of Physics, New York, v. 50, n. 1, p. 66-71, 1982.

DI SESSA, A. Unlearning aristotelian Physics: a study of knowledge-based learning. Cognitive Science, Norwood, v. 6, n. 1, p. 37-75, 1982.

DORAN, B. G. Misconceptions of selected science concepts held by Elementary School students. Journal of Research in Science Teaching, New York, v. 9, n. 2, p. 127-137, 1972 .

DRIVER, R. Student's conceptions and the learning of science. International Journal of Science Education, London, v. 11, special issue, p. 481-490, 1985.

DRIVER, R.; EASLEY, J. Pupils and paradigms: a review of literature related to concept development in adolescent science students. Studies in Science Education, Leeds, v. 5, n. 1, p. 61-84, 1978.

FERREIRO, E. Atualidade de Jean Piaget. Porto Alegre: ArtMed, 2001.

HARRES, J. B. S. Desenvolvimento histórico da dinâmica: referente para a evolução das concepções dos estudantes sobre força e movimento. Revista Brasileira de Pesquisa em Educação em Ciências, Belo Horizonte, v. 2, n. 2, p. 89-101, 2002.

McDERMOT'T, L. C. Research on conceptual understanding in Mechanics. Physics Today, New York, v. 37, n. 7, p. 24-32, 1984.

NARDI, R.; GATTI, S. R. T. Uma revisão sobre as investigações construtivistas nas últimas décadas: concepções espontâneas, mudança conceitual e ensino de ciências. Ensaio, Belo Horizonte, v. 6, n. 2, p. 145-166, 2005.

PEDUZZI, L. O. Q.; PEDUZZI, S. S. O conceito de força no movimento e as duas primeiras leis de Newton. Caderno Catarinense de Ensino de Física, Florianópolis, v. 2, n. 1, p. 6-15, 1985.

POZO, J. I. La historia se repite: Las concepciones espontáneas sobre el movimiento y la gravedad. Infancia y Aprendizaje, Madrid, v. 38, n. 38, p. 69-87, 1987.

ROGAN, J. M. Development of a conceptual framework of heat. Science Education, New York, v. 72, n. 1, p. 103-113, 1988.

SAXENA, A. B. An attempt to remove misconceptions related to electricity. International Journal of Science Education, London, v. 14, n. 2, p. 157-162, 1992. 
Análise da relação entre força e movimento ...

SEBASTIA, J. M. Fuerza y movimiento: la interpretación de los estudiantes. Enseñanza de las Ciencias, Barcelona, v. 2, n. 3, p. 161-169, 1984.

SOLOMON, J. Learning about energy: how pupils think in two domains. European Journal of Science Education, London, v. 5, n. 1, p. 49-59, 1983.

VIENNOT, L. Spontaneous reasoning in elementary dynamics. European Journal of Science Education, London, v. 1, n. 2, p. 205-222, 1979.

WATTS, D.; ZYLBERSZTAJN, A. A survey of some children's ideas about force. Physics Education, Bristol, v. 16, n. 6, p. 360-365, 1981.

Artigo recebido em novembro de 2009 e aceito em maio de 2010. 